\title{
II. LA CULTURA DE LA LEGALIDAD COMO POLÍTICA PÚBLICA. HACIA UNA TEORÍA DEMOCRÁTICA DEL DERECHO POSITIVO MEXICANO.
}

\author{
Por. Eduardo de Jesús CASTELLANOS HERNADEZ*
}

Sumario I. Resumen. II. Consideraciones previas. III. Políticas Públicas y planeación del desarrollo. IV. Origen de una política pública. V. Compilación jurídica nacional. VI. Febrero, mes de la Constitución. VII. Proceso de una política pública. VIII. Investigaciones, publicaciones y eventos. IX. Plan Nacional de Desarrollo 2007-2012. X. Acuerdo nacional por la seguridad, la justicia y la legalidad. XI. Consideraciones finales.

Resumen

El fomento de la cultura de la legalidad es una política pública de los tres órdenes de gobierno del Estado Mexicano, cuyos antecedentes parten desde la teoría del derecho, se insertan en la administración pública y la academia, hasta llegar a la visión prospectiva que la convierte en una de las más promisorias líneas de acción de la planeación y programación del desarrollo nacional, a tomar en cuenta por todos los operadores jurídicos nacionales.

Consideraciones previas

La cultura de la legalidad como concepto expreso pareciera un tema ajeno a la reflexión de los juristas tradicionales y actuales, aunque sin duda ha estado implícito en sus análisis sobre la existencia, eficacia, validez, legitimidad o legitimación de las normas jurídicas.

En su Teoría General del Derecho y del Estado ${ }^{2}$, Kelsen señala que la validez de un orden jurídico depende de su eficacia y pierde su validez cuando la realidad deja de coincidir con él, sin especificar si se refiere a la realidad normada o a la realidad de la aplicación u observancia de la norma jurídica.

En su Introducción al Análisis del Derecho, Carlos Santiago $\mathrm{Nino}^{3}$ se refiere a los diferentes sentidos de "validez": existencia, justificabilidad, obligatoriedad, autorización derivada de otra norma, pertenencia a un sistema jurídico y observancia. Por cuanto a la observancia, recuerda que se dice que una norma o un sistema jurídico son válidos cuando tienen vigencia o eficacia, "o sea que son generalmente observados y aplicados".

Nino se refiere a la existencia de las normas como concepto descriptivo, para lo cual parte de las confusiones que atribuye a la teoría de Kelsen, por lo cual separa el concepto de validez (o existencia) normativo de los conceptos de validez (o existencia) descriptivos. Reserva entonces la palabra "validez" para hacer referencia a la justificabilidad o fuerza obligatoria de las normas jurídicas, en tanto que a la palabra "existencia" le atribuye un significado exclusivamente descriptivo.

$(*)$ Licenciado en Derecho por la UNAM; maestro en Administración de Empresas por la UAEM; doctorado en Estudios Políticos por la Universidad de París. Profesor de las facultades de Ciencias Políticas y Sociales y de Derecho de la UNAM. Director general de Compilación y Consulta del Orden Jurídico Nacional de la Secretaría de Gobernación.

\footnotetext{
${ }^{2}$ UNAM, p. 142 y sigs.

${ }^{3}$ Ariel. Derecho, p. 132 y sigs.
} 
Se pregunta, entonces, ¿cuándo una norma jurídica es eficaz o vigente?, para lo cual señala dos condiciones: que sus destinatarios la observen (aunque pueda haber desviaciones), y que los órganos de aplicación las reconozcan en sus decisiones.

En Derecho y razón. Teoría del garantismo penaf $f^{4}$ Luigi Ferrajoli se refiere a la legitimidad y a la legitimación del derecho penal, las cuales asimila en general al derecho positivo y a cada una de sus normas o instituciones, pero en cualquier caso les asigna un sentido externo y otro interno. En el primero habla de criterios de valoración morales o políticos o de utilidad extra o meta jurídica, en tanto que en el segundo alude a principios normativos internos o intra-jurídicos.

Para Luis Prieto Sanchís, en sus Apuntes de teoría del Derecho ${ }^{5}$, las condiciones de validez de la norma jurídica, por cuanto a su forma y contenido, son independientes de que las normas reúnan o no otras cualidades, entre las cuales señala que sean justas, efectivas para las finalidades sociales que se proponen, o bien que sean más o menos respetadas y cumplidas o sus destinatarios

La creación de las normas jurídicas en México al igual que en cualquier otra parte del mundo, así como la construcción y análisis de las políticas públicas, como habremos de ver en seguida, no pueden sustraerse de su contexto social y económico inmediato. Es el caso de la influencia que en el derecho positivo mexicano tienen la transición política y la alternancia democráticas, ésta en el ejercicio del poder ejecutivo federal a partir del año 2000 , pero con su antecedente necesario que fue la pérdida gradual del partido hegemónico, primero, de la mayoría calificada de dos tercios en la Cámara de Diputados, necesaria para la reforma automática de la Constitución, más tarde, de la mayoría absoluta necesaria para la aprobación automática de leyes y acuerdos, y posteriormente de la titularidad del ejecutivo federal.

No sólo los politólogos y los sociólogos jurídicos sino también todos los operadores jurídicos en México, tienen que tomar en cuenta estos datos duros en el proceso legislativo de creación de la ley, en el administrativo de producción reglamentaria, así como en el jurisdiccional de solución de controversias e interpretación. De otra forma, la relación entre sociedad y derecho ocurriría frente a nosotros sin siquiera percatarnos. La construcción y el análisis de la política pública para el fomento de la cultura de la legalidad nos permiten rescatar esta afirmación para su evaluación y consecuencias.

Iniciemos, por lo tanto, con la siguiente propuesta de concepto de cultura de la legalidad: cumplimiento espontáneo y estricto por gobernantes y gobernados de las obligaciones que la ley (el orden jurídico) impone para garantizar la convivencia social, a partir de su publicación, difusión, comprensión y adopción personal; acatamiento sustentado en la conciencia y convicción, individual y colectiva, de respeto a la ley, como práctica cotidiana de valores éticos, universales, y forma de vida.

\section{Políticas Públicas y planeación del desarrollo}

Puesto que pretendo demostrar la vinculación y retroalimentación entre políticas públicas y derecho, a partir de la descripción de una política pública específica, la de fomento de la cultura de la legalidad, una vez planteado el contexto teórico respecto del impacto de la observancia del derecho en la teoría jurídica, me parece conveniente establecer el contexto doctrinal de las políticas públicas.

Harold D. Lasswell, en su artículo La orientación hacia las políticas, señala que la palabra "política" (policy) se utiliza habitualmente para identificar las elecciones más importantes en las organizaciones y en la vida privada. Se habla así de "política gubernamental", "política empresarial" o incluso de "mi propia política", para señalar de esta manera elecciones sobre problemas centrales.

\footnotetext{
${ }^{4}$ Editorial Trotta, p. 213 y sigs.

${ }^{5}$ Editorial Trotta, p. 73 y sigs.

${ }^{6}$ En: Luis F. Aguiar Villanueva (Estudio introductorio y edición). el estudio de la políticas públicas. Miguel Ángel Porrúa, p. 83 y sigs. Revista Jurídica del Departamento de Derecho Academia de Derecho Administrativo Tercera Época. Año 2. No 2. Vol. 1.Enero-Junio 2010
} 
Asimismo, precisa que un conjunto de disciplinas sociales se han ocupado de explicar los procesos de elaboración y ejecución de las políticas. Las estrategias de política, a su vez, según Yehezkel Dror ${ }^{7}$, determinan las posturas, supuestos y líneas directrices a seguir por las políticas específicas.

En el capítulo dedicado a La concepción emergente de las ciencias de políticas, incluido en la misma compilación en cita, Lasswell considera que éstas se ocupan del conocimiento del y en el proceso de toma de decisiones en el orden público y privado. Es en éste énfasis en el análisis del proceso de toma de decisiones donde radica la diferencia, afirma, entre las ciencias de las políticas y otras formas de actividad intelectual.

Respecto a la implementación de las políticas públicas, se ha escrito que se trata de "un proceso organizacional dinámico cuya configuración resulta de las recurrentes interacciones entre las metas y los métodos del proyecto y el contexto institucional” ${ }^{8}$.

Esta perspectiva de políticas públicas cuyo origen se encuentra en los Estados Unidos a partir de la política del New Deal, durante el gobierno del presidente Franklin Rosselvet, y el periodo de posguerra, encuentra un desarrollo amplio en la administración pública mexicana, cuya culminación podría situarse con la reforma constitucional de 1983 que introdujo un articulado expresamente dedicado a regular la política económica, que condujo a su vez a la promulgación y publicación de la Ley (federal) de Planeación, así como de las leyes locales de planeación.

En la historia administrativa pública del país, si bien las políticas públicas derivadas, en primer lugar, de los presupuestos anuales de egresos y sus correspondientes leyes de ingresos, encontraron en los diferentes esfuerzos planificadores (planes cardenistas, planes nacionales de inversiones, Plan Global de Desarrollo, etc.) una mayor sistematización hasta llegar a la reforma constitucional y legal mencionadas, donde ubico el punto de coincidencia expreso entre políticas públicas, planeación del desarrollo y legislación nacional. La Ley de Planeación, por cierto, no tiene reglamento, pero a partir de su expedición, invariablemente, conforme a su mandato, dentro de los seis primeros meses de cada nueva administración del Ejecutivo federal, se consulta, prepara y publica el correspondiente plan nacional de desarrollo.

El libro de Eugene Bardach, Los ocho pasos para el análisis de Políticas Públicas ${ }^{9}$, sintetiza las complejidades y obstáculos a los que el analista (y el diseñador y constructor) de políticas públicas se enfrenta en el desempeño de su trabajo, esto es, la investigación y análisis de problemas públicos, a fin de crear alternativas de políticas viables, justas y eficientes. La utilidad del libro consiste en explicar y ordenar las etapas, congruencias y contradicciones propias del proceso de análisis (y diseño, y forja) de la acción gubernamental.

El camino de los ocho pasos que propone es el siguiente: definición del problema; obtención de información; construcción de alternativas; selección de criterios; proyección de los resultados; confrontación de costos; decisión; y difusión para retroalimentación. Entre los criterios prácticos que sugiere para el análisis de alternativas de políticas y los procesos de implementación sugiere los siguientes criterios: legalidad, viabilidad política, solidez en condiciones de implementación administrativa y perfectibilidad.

Para efecto del diseño e implementación de la política pública de fomento de la cultura de la legalidad en México, me importa destacar que Bardach ${ }^{10}$ refiere en la evaluación de criterios de

\footnotetext{
${ }^{7}$ Prolegómenos para las ciencias de políticas. Ob. cit., p. 119 y sigs.

${ }^{8}$ Luis F. Aguilar Villanueva (Estudio introductorio y edición). LA IMPLEMENTACIÓN DE LAS POLítICAS. Miguel Ángel Porrúa, p. 83.

${ }^{9}$ Miguel Ángel Porrúa. CIDE. Primera edición, marzo de 1998. Cuarta reimpresión, diciembre de 2008.

${ }^{10}$ Ob. cit., p. 42 
evaluación de políticas uno que fue el caso en la política que se reseña: "El proceso político se hace cargo de él. Uno de los enfoques consiste simplemente en dejar que los procesos gubernamentales y políticos existentes efectúen la ponderación". Sin duda éste fue el caso para el fomento de la cultura de la legalidad: nuevamente, la transición política y la alternancia democráticas dieron, y siguen dando, un contexto favorable para su creación y desarrollo.

\section{Origen de una política publica}

La política pública de fomento de cultura de la legalidad en México surge a partir del conjunto de reformas a la Ley Orgánica de la Administración Pública Federal, durante la etapa previa al inicio de la gestión del presidente Vicente Fox, gobierno de la alternancia democrática entre los dos partidos políticos nacionales con mayor intención de voto, el Partido Revolucionario Institucional y el Partido Acción Nacional, habiendo correspondido a éste la victoria electoral. Dichas reformas fueron publicadas en el Diario Oficial de la Federación de . de ... de 2000, y en el caso específico, consistió en una adición al artículo 27 que regula las atribuciones de la Secretaría de Gobernación.

El texto, vigente, de la nueva atribución de la Secretaría contenida en dicho Ordenamiento y numeral, e introducida con la reforma citada, es el siguiente:

"XXXI. Compilar y sistematizar las leyes, tratados internacionales, reglamentos, decretos, acuerdos y disposiciones federales, estatales y municipales, así como establecer el banco de datos correspondiente, con objeto de proporcionar información a través de los sistemas electrónicos de datos;"

Como consecuencia de esta nueva atribución y con el propósito de materializarla en el ámbito administrativo público, se creó la Dirección General de Compilación y Consulta del Orden Jurídico Nacional, dependiente de la Subsecretaría de Asuntos Jurídicos y Derechos Humanos, también de nueva creación al igual que la Unidad para la Promoción y Defensa de los Derechos Humanos. Dicha Subsecretaría que incluye también a la Unidad de Asuntos Jurídicos, junto con la Subsecretaría de Enlace Legislativo, señalaron en la estructura administrativa de la Dependencia las nuevas características que habría de tener la Secretaría, cuyo primer titular fue el licenciado Santiago Creel Miranda, en esa etapa inédita de la vida institucional del país.

Esa nueva estructura administrativa quedó establecida en el nuevo Reglamento Interior de la Secretaría de Gobernación, publicado en el Diario Oficial de la Federación de fecha 30 de julio de 2002, cuyo artículo 22 vigente señala las siguientes atribuciones a la Dirección General de Compilación y Consulta del Orden Jurídico Nacional:

"Artículo 22.- La Dirección General de Compilación y Consulta del Orden Jurídico Nacional tendrá las siguientes atribuciones:

I. Compilar las leyes, tratados internacionales, reglamentos, decretos, acuerdos y demás disposiciones federales, estatales y municipales o delegacionales, así como establecer el banco de datos correspondiente;

II. Mantener actualizado el texto vigente de las disposiciones que constituyen el orden jurídico nacional a que se refiere la fracción anterior;

III. Sistematizar la información de naturaleza jurídica que envíen las entidades federativas en el marco de los acuerdos de coordinación respectivos y en los términos de la normatividad aplicable;

Revista Jurídica del Departamento de Derecho

Academia de Derecho Administrativo

Tercera Época. Año 2. No 2. Vol. 1.Enero-Junio 2010 
IV. Compilar y ordenar las normas que impongan modalidades a la propiedad privada dictadas por el interés público;

V. Poner a disposición del público, para su consulta a través de los sistemas electrónicos de datos, las normas actualizadas que constituyen el orden jurídico nacional;

VI. Difundir y promover la consulta al banco de datos que contenga el orden jurídico nacional;

VII. Realizar e impulsar publicaciones, estudios e investigaciones relativos al orden jurídico nacional y su consulta, a las atribuciones de la Secretaría y de su sector coordinado, así como coordinar, realizar y participar en estudios, investigaciones, cursos y demás eventos destinados a difundir la informática jurídica;

VIII. Promover la capacitación y actualización de los servidores públicos y del público en general, para el aprovechamiento óptimo del banco de datos relativo al orden jurídico nacional;

IX. Proponer a su superior jerárquico la normatividad técnica relativa a la instrumentación, operación y actualización del banco de datos relativo al orden jurídico nacional;

X. Proponer a su superior jerárquico, en coordinación con la Unidad de Asuntos Jurídicos, los acuerdos, convenios y demás instrumentos jurídicos relativos al cumplimiento de las atribuciones anteriores;

$X I$. Administrar y dirigir la base de datos relativa al registro nacional de avisos de testamento de conformidad con los convenios y demás disposiciones jurídicas aplicables;

XII. Certificar el texto de la promulgación de las leyes y demás disposiciones jurídicas federales, a solicitud fundada y motivada de las autoridades y personas interesadas;

XIII. Formar parte del Comité Jurídico Interno de la Secretaría, y

XIV. Las demás que determine el Secretario, dentro de la esfera de sus facultades."

Una forma de agrupar las atribuciones y servicios públicos a cargo de la Dirección General es la siguiente:

- Fomento de la Cultura de la Legalidad

- Compilación Jurídica Nacional

- Certificación de disposiciones jurídicas federales

- Investigaciones, Publicaciones y Eventos sobre el Orden Jurídico Nacional

- Difusión de la Informática Jurídica

- Registro Nacional de Avisos de Testamento

- Registro Nacional de Avisos de Testamento (en construcción)

En el diseño e instrumentación de la estructura administrativa de la Dirección General, se tuvo una filosofía organizacional sustentada en el trabajo de equipo multi e interdisciplinario para impulsar, a su vez, un trabajo de colaboración y coordinación intergubernamental en un ámbito federal con pluralidad política. Se integra actualmente con cuatro direcciones de área: Investigación y Compilación; Divulgación y Concertación; Sistemas de Consulta y Formación Jurídica, y Bancos Jurídicos Intergubernamentales. 
La integración del personal adscrito a esta unidad administrativa (53) reúne, como ya se ha mencionado, servidores públicos con diferentes formaciones profesionales, entre los que sobresalen, actualmente, desde luego, licenciados en Derecho (17), pero también licenciados e ingenieros en Sistemas e Informática (5), Diseño Gráfico (5), Periodismo y Comunicación Social (5), Ciencias Políticas y Administración Pública (3), Contaduría (1), Pedagogía y Psicología (2), así como personal de apoyo operativo.

Durante los poco más de seis años de funcionamiento, la Dirección General y la política pública de fomento de la cultura de la legalidad ha recibido el impulso de los sucesivos secretarios de Gobernación: Santiago Creel Miranda, Carlos María Abascal Carranza, Francisco Javier Ramírez Acuña, Juan Camilo Mouriño Terrazo y Fernando Francisco Gómez Mont Urueta.

Asimismo, de los sucesivos subsecretarios de Asuntos Jurídicos y Derechos Humanos: Daniel Francisco Cabeza de Vaca Hernández, Arturo Chávez Chávez, Pablo Muñoz y Rojas, Miguel Alessio Robles y Daniel Francisco Cabeza de Vaca Hernández.

\section{Compilación jurídica nacional}

Se ha señalado ya que el origen de la estructura administrativa de la Dirección General de Compilación y Consulta del Orden Jurídico Nacional estuvo en la adición de la fracción XXXI del artículo 27 de la Ley Orgánica de la Administración Pública Federal, así como en la voluntad política de cambio y democratización de la Administración Pública Federal ${ }^{11}$ en un periodo de transición política y alternancia democráticas.

No se trató, desde luego, de un hecho aislado, como lo acreditan nuevos ordenamientos tales como la Ley Federal de Responsabilidades Administrativas de los Servidores Públicos, la Ley Federal de Transparencia y Acceso a la Información Pública Gubernamental, la Ley del Servicio Profesional de Carrera en la Administración Pública Federal, la Ley de Seguridad Nacional, la Ley de Responsabilidad Patrimonial del Estado, la Ley de Desarrollo Social y la Ley de Responsabilidad Hacendaria, entre otros.

Ahora bien, la política pública tuvo como origen a su vez la compilación del orden jurídico nacional y su puesta a disposición del público en general por medios electrónicos. La denominación de la nueva unidad administrativa así como la concepción de su cometido, fueron coincidentes con la perspectiva de Norberto Bobbio en su Teoría General del Derecho ${ }^{12}$, respecto del ordenamiento jurídico entendido como una unidad compuesta por "una miríada de normas que, como las estrellas en el firmamento, son imposibles de contar".

En efecto se trataba de compilar todas las disposiciones de carácter general y obligatorio, impersonal y abstracto, expedidas por las autoridades competentes de los diferentes órdenes de gobierno. Es decir, además de los tres poderes y los siete órganos constitucionales autónomos federales, treinta y dos entidades federativas y dos mil cuatrocientos cuarenta municipios, si bien hay que excluir a poco más de cuatrocientos municipios del estad de Oaxaca que en su ámbito municipal interno se rigen por el sistema de usos y costumbres y, en consecuencia, para este único efecto no son de derecho escrito.

Una tarea de esta magnitud no podía ser realizada por una oficina administrativa desde la Ciudad de México, de tal forma que como ya se dijo desde su inicio se tuvo una perspectiva de colaboración y coordinación intergubernamental, materializada actualmente mediante los convenios respectivos suscritos con los poderes y órganos autónomos federales y los gobiernos locales de las entidades

\footnotetext{
${ }^{11}$ Consultar: Leyes y reglamentos para el cambio democrático en la administración pública federal. Secretaría de Gobernación. Varias ediciones y reimpresiones.

${ }^{12}$ Segunda edición. Temis. P. 141 y sigs. 
federativas. Dichos convenios tienen prevista la formación de órganos colegiados de seguimiento y evaluación del propio instrumento, integrados con servidores públicos locales o de las entidades federales, en su caso, y de la Dirección General.

Este mismo esquema de descentralización y desconcentración para llevar a cabo la compilación jurídica, se repite en el ámbito mismo de la Administración Pública Federal, compuesta de 18 secretarías, una Consejería Jurídica, la Procuraduría General de la República, ... organismos descentralizados, ... desconcentrados, .... fideicomisos públicos y .... Comisiones intersecretariales ${ }^{13}$; esquema que también se repite al interior de la propia Secretaría de Gobernación.

Desde su inicio la compilación jurídica nacional fue prevista en dos grandes etapas, una primera, centralizada, que permitió iniciar el 17 de febrero de 2002 el servicio público de compilación y consulta del orden jurídico nacional por vía electrónica, para lo cual en esa fecha empezó a difundirse la página www.ordenjuridico.gob.mx con cerca de cinco mil ordenamientos jurídico compilados, que a la fecha son poco más de cuarenta mil de un total aproximado de más de cinto cincuenta mil, puesto que hay que recordar que no sólo se compilan constituciones, tratados, leyes y reglamentos federales y leyes y reglamentos locales, sino también bandos y reglamentos municipales y, en general, toda disposición normativa de carácter general y obligatorio, impersonal y abstracto, esto es, también, planes y programas, normas técnicas, normas oficiales, circulares, oficios circulares, etc.. A la segunda etapa, descentralizada desconcentrada, sustentada en la colaboración y coordinación intergubernamental ya me he referido.

Es oportuno recordar que tan sólo en el orden federal se tienen vigentes los ordenamientos siguientes: la Constitución General, 1,294 tratados internacionales, 260 leyes y 408 reglamentos; a los cuales se agregan todas las demás disposiciones de carácter general y obligatorio.

A la fecha, la página www.ordenjuridico.gob. $m x$ ha recibido poco más de cuatro y medio millones de visitas, cuya permanencia en su mayoría dura de veinte minutos a más de una hora; lo cual significa que se ha convertido en un instrumento de estudio y de investigación. Sin embargo, el propósito es que sus visitantes no sean sólo profesores, investigadores y estudiantes de Derecho, como probablemente sean en su mayoría hasta la fecha, sino la población en general. Es por ello que, desde su inicio, también, se ha procurado darle una configuración muy amigable, accesible, para que no sólo los especialistas en Derecho puedan encontrar fácilmente la información jurídica que busquen, sino también cualquier persona interesada. Para ello, además, hemos diversificado los servicios de la página como habremos de señalar más adelante.

IV. Febrero, mes de la Constitución.

Una forma de promover a población abierta la cultura de la legalidad y la visita a la página www.ordenjuridico.gob.mx ha sido la campaña nacional anual "Febrero, mes de la Constitución y del Estado Democrático de Derecho", iniciada el año 2005 y repetida en los años posteriores.

\section{Proceso de una política pública.}

Si bien ya se ha señalado que el inicio de esta política pública de fomento de cultura de la legalidad estuvo en la compilación reseñada cuyo origen fue legislativo, el desarrollo de la misma se fue dando sobre la marcha, a partir de las propias atribuciones de la Dirección General, las cuales fueron aprovechadas para integrar, fortalecer, dar permanencia y permitir la expansión de la política pública así surgida. Pero, ¿cuáles fueron esas fortalezas institucionales que permitieron la expansión de la política en cuestión?.

\footnotetext{
${ }^{13}$ Diario Oficial de la Federación de ... de .... De ...... p.

Revista Jurídica del Departamento de Derecho Academia de Derecho Administrativo 


\section{Registro Nacional de Avisos de Testamento}

La primera, a mi juicio, fue que por decisión expresa del secretario Santiago Creel la nueva unidad administrativa, la Dirección General de Compilación y Consulta del Orden Jurídico Nacional, tuvo bajo su responsabilidad la gestación del Registro Nacional de Avisos de Testamento ${ }^{14}$, hasta entonces a cargo de la Dirección General de Asuntos Jurídicos, hoy Unidad de Asuntos Jurídicos. Se trata de un servicio público que consiste en la aplicación de la informática jurídica para contribuir a la certeza y seguridad jurídica en la transmisión del patrimonio familiar por vía hereditaria; sustentado igualmente en la colaboración y coordinación intergubernamental, cuya fase de concertación y suscripción de convenios se había iniciado en la anterior administración de la Secretaría y continuado por la encabezada por el secretario Creel.

Puesto que en nuestro régimen federal de gobierno los estados de la República son libres y soberanos por cuanto a su régimen interior y el Distrito Federal tiene una autonomía administrativa y legislativa equivalente, sucedía que -como en muchos otros casos- no compartían la información de avisos de testamento otorgados en su territorio. Hoy, la base de datos nacional de avisos de testamento está actualizada y, en tiempo real, la Secretaría de Gobernación, a través de la Dirección General de Compilación y Consulta del Orden Jurídico Nacional, a solicitud fundada y motivada de las autoridades competentes de las entidades federativas (responsables de los Archivos de Notarías), entrega con firma electrónica avanzada un reporte de búsqueda nacional de avisos del testamento o testamentos que hubiese otorgado en vida el autor de la sucesión de que se trate.

En la mitad de las entidades federativas ha habido reformas a diferentes ordenamientos de su legislación local (Código Civil, Código de Procedimientos Civiles, Ley de Notariado, Ley Orgánica de la Administración Pública) o a uno solo, para hacer obligatorio dicho reporte de búsqueda nacional durante un procedimiento sucesorio.

Este nuevo servicio público fue construido y funciona gracias al concurso de la Asociación Nacional del Notariado Mexicano, los Colegios y Consejos de Notarios de las entidades federativas, los responsables de los Archivos de Notarías de estas entidades y la Secretaría de Gobernación. A partir de este trabajo conjunto, surgió en 2003 la idea de promover, primero, la campaña nacional "Septiembre, mes del testamento" y, a partir de 2007, la campaña nacional "Testamento a bajo costo para personas de escasos recursos". En esencia, ambas campañas entrañan el fomento de la cultura de la legalidad llevada al ámbito individual de las personas físicas. En la práctica, han contribuido a la movilización nacional por la cultura de la legalidad.

\section{Registro Nacional de Avisos de Poderes Notariales}

La alianza estratégica con los interlocutores institucionales mencionados ha permitido, también, el diseño, planeación e inicio de la implementación de otra base de datos que reúna los avisos de poderes notariales otorgados en las entidades federativas, a efecto de aprovechar nuevamente la informática para la certeza y seguridad en el tráfico jurídico sustentado en dichos instrumentos notariales. A la fecha, quince entidades federativas han suscrito con la Secretaría de Gobernación los convenios de colaboración respectivos, en los que participan como testigos la Asociación Nacional del Notariado Mexicano y el Colegio o Consejo de Notarios local correspondiente.

\section{Consejo Consultivo}

\footnotetext{
${ }^{14}$ Consultar: Encuentro nacional para la consolidación del registro de avisos de testamento. Secretaría de Gobernación. Asociación Nacional del Notariado Mexicano. México, 2004. Disponible en la Biblioteca Jurídica Virtual de la página www.ordenjuridico.gob.mx Revista Jurídica del Departamento de Derecho Academia de Derecho Administrativo Tercera Época. Año 2. No 2. Vol. 1.Enero-Junio 2010
} 
Otro de los datos a destacar de esta colaboración intergubernamental y con la sociedad civil organizada en su colegiación profesional, el cual ha facilitado enormemente la comunicación y coordinación, es que a partir de los convenios suscritos, cada tres meses, se reúne en algún lugar de la República el Consejo Consultivo de Avisos de Testamento y de Poderes Notariales, integrado por dichos interlocutores, para el seguimiento y evaluación de los proyectos y servicios mencionados.

VI. Investigaciones, publicaciones y eventos.

El programa editorial de la Dirección General de Compilación y Consulta del Orden Jurídico Nacional de la Secretaría de Gobernación inició con folletos promociónales y libros con las memorias institucionales de los eventos realizados, así como con publicaciones en formato electrónico (discos compactos y DVD) de compilaciones jurídicas sobre los diferentes ámbitos regulados por el orden jurídico nacional. A las investigaciones documentales y los trabajos de análisis realizados internamente se agregaron colaboraciones de servidores públicos y académicos que aportaron materiales.

Actualmente, dicha obra editorial, además de su impresión en papel o de su reproducción en disco compacto o DVD en más de cuatrocientos mil ejemplares distribuidos en todo el país, aparece en la Biblioteca Jurídica Virtual de la página www.ordenjuridico.gob.mx, donde puede ser consultada.

\section{Congreso anual}

La Dirección General de Compilación y Consulta del Orden Jurídico Nacional, como ya se ha referido, inició sus trabajos en el mes de septiembre de 2002 y a partir del año 2003, en el mes de octubre, organiza cada año un congreso anual que reúne a poco más de tres mil profesores, investigadores y estudiantes del nivel superior de enseñanza.

La estrategia organizacional del congreso es a través de conferencias y paneles en los que han participado habitualmente secretarios de Estado, ministros de la Suprema Corte de Justicia de la Nación, magistrados de tribunales federales y locales, dirigentes de órganos constitucionales autónomos federales y locales, legisladores y funcionarios federales y locales, así como profesores, investigadores y especialistas nacionales y extranjeros. En ocasiones se han organizado también mesas de discusión para la presentación de ponencias aportadas por los participantes interesados.

La memoria virtual, en audio y video, de todos y cada uno de estos eventos académicos puede ser consultada en la Biblioteca Jurídica Virtual referida.

\section{Exposición anual itinerante}

Desde un principio se aprovechó la técnica gráfica del cartel como un medio de comunicación idóneo para promover y difundir los servicios de la Dirección General. Sin embargo, fue a partir del año 2005 en que por primera vez se presentó en gran formato una exposición en la sala principal de la Biblioteca de México "José Vasconcelos", en la Plaza de la Ciudadela en la Ciudad de México.

Los temas de dicha exposición anual han sido los siguientes: "Cultura de la legalidad en el sistema federal y la pluralidad democrática" (2005), "Cultura de la legalidad para la consolidación democrática" (2006), "La Procuración e Impartición de Justicia en el Estado Mexicano" (2007), “Antecedentes Históricos y Constituciones Políticas de los Estados Unidos Mexicanos" (2008) y "Planes y Programas Jurídicos y Políticos de la República Mexicana" (2009).

La exposición, además de presentarse en gran formato, se reproduce en tamaño cartel $(7,500$ copias en 2008 y 13,000 en 2009) y se ha presentado en la Sala Adamo Boari del Palacio de Bellas Artes, el Patio de los Cañones del Museo Nacional de Historia y Castillo de Chapultepec, el Tribunal Superior de 
Justicia del Distrito Federal, las estaciones Tacubaya y ... del Sistema de Transporte Colectivo Metropolitano de la Ciudad de México, las cuatro terminales de autobuses de la Ciudad de México y otros espacios públicos. Además, se distribuye gratuitamente para su exhibición en las escuelas y facultades de Derecho de todo el país, en áreas jurídicas de los gobiernos Federal y locales, y en las bibliotecas públicas de la Red Nacional de Bibliotecas de CONACULTA.

\section{Concurso nacional anual de tesis}

Con el propósito de impulsar la investigación jurídica se convoca cada año a todos los estudiantes egresados de las escuelas y facultades de Derecho de todo el país, a presentar sus tesis de licenciatura, maestría y doctorado que aborden temas relativos a las disposiciones del orden jurídico nacional en los ámbitos del derecho público, privado y social. El Secretario de Gobernación entrega los reconocimientos a los triunfadores.

\section{Reunión nacional de directores de diarios, periódicos, gacetas y boletines oficiales}

La publicación oficial de todas las disposiciones del orden jurídico nacional en los diferentes órdenes de gobierno, contrariamente a lo que pudiera suponerse, no es un asunto resuelto, aunque se trate de una prerrogativa democrática elemental y de un elemento básico para la seguridad y la certeza jurídica. De una parte, no en todas las entidades federativas existe un ordenamiento local, ley o reglamento, que regule la publicación oficial de las disposiciones jurídicas; asimismo, no en todas las entidades federativas este servicio público se encuentra disponible en la red electrónica de datos o Internet, pues todavía varios periódicos oficiales locales todavía sólo se publican en prensa plana. La aparición y eventual multiplicidad de gacetas municipales así como la falta de recursos presupuestales municipales para el pago de derechos, necesario para la publicación en los periódicos oficiales locales de su reglamentación municipal, son otros desafíos a enfrentar.

Es por ello que, en el año 2006, se llevó a cabo en el Salón Revolución de la Secretaría de Gobernación la primera Reunión Nacional de Directores de Diarios, Periódicos, Gacetas y Boletines Oficiales de los Estados Unidos Mexicanos", misma que se repetirá en 2009 para evaluar avances y desafíos. La memoria escrita del primer evento puede ser consultada en la Biblioteca Jurídica Virtual.

VII. Plan Nacional de Desarrollo 2007-2012

\section{Foros de consulta}

En los términos de lo dispuesto por la Ley de Planeación previamente invocada, durante los meses de abril y mayo de 2007, la Secretaría de Gobernación organizó foros de consulta popular sobre el tema "Fomento de la Cultura de la Legalidad y Fortalecimiento del Estado Democrático de Derecho"; los cuales se realizaron invariablemente con el apoyo de las autoridades locales en las ciudades de Chetumal, Quintana Roo; Hermosillo, Sonora; Guadalajara, Jalisco, y México, Distrito Federal. La Memoria de dichos eventos fue publicada impresa y en formato virtual que también puede ser consultado en la Biblioteca Jurídica Virtual de la página www.ordenjuridico.gob.mx.

\section{Primera encuesta nacional}

Paralelamente a la organización y realización de los foros mencionados, se aplicó una encuesta nacional, cuyas preguntas y resultados se transcriben a continuación para comentarlos en seguida:

1. ¿Al iniciar cualquier juego o competencia deportiva es necesario que los participantes conozcan las reglas conforme a las cuales se desarrollará? Si $99 \%$, No $1 \%$ 
2. ¿Los ciudadanos mexicanos deben conocer las reglas para relacionarse entre si y con las autoridades? Si $95 \%$, No $5 \%$

3. ¿Ha leído la Constitución Política de los Estados Unidos Mexicanos? Sólo una parte 51\%, Si 40, No $9 \%$

4. ¿Conoce los derechos y obligaciones que le otorga la Constitución Política de los Estados Unidos Mexicanos? Sólo una parte $54 \%$, Si $43 \%$, No $3 \%$

5. ¿Conoce la Constitución Particular del Estado de la República donde usted habita o el Estatuto de Gobierno del Distrito Federal si es que habita en la Ciudad de México? Sólo una parte $51 \%$, Si $19 \%$, No $30 \%$

6. ¿Considera usted que la población nacional conoce las leyes? Sólo una parte $57 \%$, Si $2 \%$, No $41 \%$

7. ¿Considera usted que la población nacional cumple con la ley? Sólo una parte $72 \%$, Si $1 \%$, No $27 \%$

8. ¿Considera usted que las autoridades públicas cumplen con la ley? Sólo una parte $68 \%$, Si $3 \%$, No $29 \%$

9. ¿Es necesario que la población en general conozca la Constitución y las leyes? Si $99 \%$, No $1 \%$

10. ¿A quién corresponde la responsabilidad de difundir la Constitución y las leyes? Al gobierno $38 \%$, A la escuela $6 \%$, A la familia $1 \%$, A los partidos políticos $1 \%$, A los sindicatos $0 \%$, A las organizaciones no gubernamentales $0 \%$, A todos los anteriores $53 \%$, Otros $1 \%$

Como ya se ha mencionado, la encuesta fue aplicada aprovechando la movilización social que entrañaron los foros, de tal suerte que se interrogó a los asistentes pero también se visitaron escuelas y facultades de Derecho de las ciudades donde se llevó a cabo la consulta que se comenta. Esto explica los altos porcentajes de conocimiento de la Constitución general, de las particulares de los Estados y del Estatuto de Gobierno del DF, aunque es de señalarse que el porcentaje de conocimiento de los ordenamientos fundamentales locales es menor que el de la Constitución general.

Es de destacarse la coincidencia entre las respuestas relativas a la necesidad de conocer las reglas de un juego deportivo y la de conocer la Constitución y las leyes, en ambos casos la respuesta afirmativa fue de $99 \%$. Pero más significativa es la percepción ciudadana respecto del cumplimiento de la ley por parte de la población y de las autoridades, puesto que según los encuestados sólo el $1 \%$ de la población en general cumple con la ley y sólo el $3 \%$ de las autoridades públicos lo hace por su parte.

\section{Visión 2030, objetivo nacional y objetivos especificos}

La encuesta y sus resultados fueron conocidos y analizados por diversas instancias de las secretarías de Gobernación y de Hacienda y Crédito Público, así como por la Oficina de la Presidencia de la República, responsables todos de la preparación del Plan Nacional de Desarrollo 2007-2012 ${ }^{15}$. La consecuencia inmediata fue que el fomento de la cultura de la legalidad quedó convertido en una política pública adoptada al más alto nivel del Gobierno federal, puesto que la Visión 2030, esto es, la visión prospectiva del Plan -"México como un país de leyes"-, así como su objetivo nacional 2 -"afianzar una sólida cultura de la legalidad"- y el objetivo 11, "Fomentar el desarrollo de una cultura de la legalidad", de su Eje 1 Estado de Derecho y seguridad, la adoptaron.

\section{Segunda encuesta nacional}

Durante los trabajos del congreso anual celebrado en la explanada del Conjunto Bucareli de la Secretaría e Gobernación en la Ciudad de México en octubre de 2008, se levantó una segunda encuesta sobre cultura de la legalidad cuyas preguntas y resultados fueron los siguientes:

1. Tengo copia certificada de mi acta de nacimiento. $\mathrm{Si}, 95 \%$; No, $5 \%$

2. Ya cuento con mi CURP. Si, $99 \%$; No, $1 \%$

\footnotetext{
${ }^{15}$ Diario Oficial de la Federación de 31 de mayo de 2007.

Revista Jurídica del Departamento de Derecho Academia de Derecho Administrativo Tercera Época. Año 2. No 2. Vol. 1.Enero-Junio 2010
} 
3. Tengo credencial de elector expedida por el IFE. Si, $93 \%$; No, $7 \%$

4. Voy a votar cuando hay elecciones. Si, $90 \%$; No, $10 \%$

5. Cuando viajo en automóvil utilizo el cinturón de seguridad. Si, 93 ; No, $7 \%$

6. En ocasiones compro cd's y películas que me gustan sin importar que sean "piratas". Si, 66;No, $34 \%$

7. Si me regresen mal un cambio a mi favor me quedo callado. $\mathrm{Si}, 11 \%$; No, $89 \%$

8. Acostumbro cruzar la calle sólo donde es permitido, esto es, en las esquinas, por los puentes o líneas peatonales. $\mathrm{Si}, 68 \%$; No, $32 \%$

9. Prefiero dar "mordida" que pagar una multa. Si, $22 \%$; No, $78 \%$

10. Suelo ser puntual en toda situación. Si, $73 \%$; No, $27 \%$

11. Si es necesario para obtener un beneficio o evitar un perjuicio, hago trampa. Si, $16 \% ;$ No, $84 \%$

12. En todos los casos solicito factura por compras o consumos realizados. $\mathrm{Si}, 34 \%$; $\mathrm{No}, 66 \%$

13. En el transporte público o en los estacionamientos ocasionalmente ocupo lugares reservados que no me corresponden. $\mathrm{Si}, 7 \%$; No, $93 \%$

14. Cuando camino por la calle prefiero tirar la basura en lugar de buscar un cesto, bote o recipiente idóneo para depositarla. Si, 18\%; No, 82

En este caso la muestra adoptada fueron los asistentes al 1er. Congreso Internacional "Cultura de la Legalidad y Políticas Públicas en el Estado Democrático de Derecho", celebrado en el Conjunto Bucareli de la Secretaría de Gobernación, en la Ciudad de México, los días 6 y 7 de octubre de 2008, al cual asistieron profesores, investigadores, estudiantes, profesionales y público en general provenientes de todas las entidades federativas. Es de hacerse notar que sólo una tercera parte de los asistentes entregaron contestada la encuesta que les fue proporcionada.

Programa sectorial de gobernación 2007-2012

Derivado del Plan Nacional de Desarrollo 2007-2012, la Secretaría de Gobernación preparó y publico el Programa Sectorial de Gobernación 2007-2012, cuyo objetivo sectorial 6 se propone: "Impulsar la actualización, adecuación y difusión del Orden Jurídico Nacional", para lo cual establece como estrategia "6.2. Fomentar la cultura de la legalidad y fortalecer el Estado Democrático de Derecho", cuya línea de acción "6.2.1. Programa para el Fomento de la Cultura de la Legalidad y el Fortalecimiento del Estado Democrático de Derecho", se encuentra a cargo de la Subsecretaría de Asuntos Jurídicos y Derechos Humanos, a través de la Dirección General de Compilación y Consulta del Orden Jurídico Nacional.

VIII. Acuerdo nacional por la seguridad, la justicia y la legalidad

En el marco de la vigésimo tercera sesión ordinaria del Consejo Nacional de Seguridad Pública, celebrada en Palacio Nacional el 21 de agosto de 2008, los Poderes Ejecutivo Federal y Estatales, Congreso de la Unión, Poder Judicial Federal, representantes de las asociaciones de Presidentes Municipales, medios de comunicación y las organizaciones de la sociedad civil, empresariales sindicales y religiosas, suscribieron el Acuerdo Nacional por la Seguridad, la Justicia y la Legalidad, publicado en el Diario Oficial de la Federación de 25 de agosto de 2008.

El compromiso XX de este Acuerdo consiste en "Instrumentar campañas para promover la cultura de la legalidad", y el XXVIII señala "Incluir en los programas de estudio la cultura de la legalidad".

IX. Consideraciones finales.

Aunque, como constatamos desde el inicio, el tema de la observancia de las normas jurídicas ha estado presente en la construcción teórica del Derecho, éste no ha llegado al punto de constituirse en un elemento esencial de la existencia, validez, eficacia, legitimidad o legitimación de las normas.

Revista Jurídica del Departamento de Derecho

Academia de Derecho Administrativo

Tercera Época. Año 2. No 2. Vol. 1.Enero-Junio 2010 
Sin embargo, en congruencia con las nuevas condiciones de creación y aplicación del Derecho en nuestro país, me parece necesario introducir el concepto de cultura de la legalidad, esto es, la aplicación y observancia efectiva del derecho sustentadas en el cumplimiento espontáneo de las normas por parte de gobernantes y gobernados, como un elemento esencial del Estado Democrático de Derecho. Sostengo, por lo tanto, que las concepciones teóricas que eluden o desechan la observancia, cumplimiento y conocimiento de las normas jurídicas como condición de su validez, eficacia, existencia o legitimación, corresponden a un estadio autoritario, no democrático, de teorización del Derecho.

Esta observación vale para Kelsen, quien escribió en una Europa no precisamente democrática, a inicios del siglo XX, no obstante que una de sus grandes aportaciones para la democratización del sistema jurídico, por ejemplo, haya sido precisamente la propuesta de control concentrado de la Constitución de Austria $^{16}$-recepción o versión europea del control difuso de la Constitución americana-. Pero vale sobre todo para los juristas españoles, durante el régimen autoritario franquista, cuya influencia en sus colegas mexicanos está siempre presente, y sobre todo los juristas mexicanos, tributarios del prolongado periodo del partido hegemónico prácticamente único y de una construcción no democrática de las normas jurídicas..

La creación de las normas, legislativas o de su reglamentación administrativa; federales, locales o municipales; debe corresponder a procesos de creación en los que intervengan autoridades democráticamente electas; en los que no sólo haya una publicación oficial de dichas normas de acuerdo a otras normas, igualmente sancionadas, para la publicación válida de aquellas, sino que además aparezca como una obligación del Estado nacional, en sus diferentes órdenes de gobierno, la de difundir dichas normas para que la población las conozca y las asuma como voluntariamente obligatorias, y dicha obligatoriedad no quede sólo en el plano hipotético formal, así sea hecha efectiva por la sanción que entrañe su incumplimiento, pues tal caso entrañaría otra forma de autoritarismo o dictadura. Paradójicamente, la dictadura de la ley, de una ley que se desconoce.

Limitar la eficacia o validez de las normas jurídicas sólo a mecanismos y procedimientos de coherencia, forma y contenido internos al sistema jurídico, sin conexión alguna con su observancia social, puede llevar a un Estado de Derecho, pero no a un Estado Democrático de Derecho, puesto que también las dictaduras militares y los regímenes autoritarios tienen reglas obligatorias a las que, igualmente, se les llama normas jurídicas.

\footnotetext{
${ }^{16}$ Sobre la recepción europea del principio de supremacía constitucional y su expresión en el sistema austriaco kelseniano de justicia constitucional, consultar: Eduardo García de Enterría. La constitución como norma y el tribunal constitucional. Thomson Civitas. 4 a edición. P 61 y sigs. 